\title{
O PÓS-ESTRUTURALISMO SISTÊMICO DE NIKLAS LUHMANN
}

\section{Léo Peixoto Rodrigues (1)}

E-mail: leo.peixotto@gmail.com

\section{Everton Garcia da Costa $(2)$}

E-mail: eve.garcoa.costa@gmail.com

(1) Instituto de Filosofia, Sociologia e Ciência Política e dos programas de Pós-Graduação em Sociologia e em Ciência Política da Universidade Federal de Pelotas (UFPel), Pelotas - RS, Brasil.

(2) Instituto Federal de Educação, Ciência e Tecnologia Sul-rio-grandense (IFSul), RS, Brasil.

DOI: $10.1590 / 3610609 / 2021$

\section{Introdução}

Este artigo inicia-se, em breves pinceladas, apresentando aspectos fundamentais da teoria sistêmica de Niklas Luhmann, discutindo, aqui e ali, ao longo de seu desenvolvimento, seus principais (e polêmicos) conceitos. O objetivo central do texto, entretanto, é destacar os elementos pós-estruturalistas que a teoria luhmanniana, mesmo que por outras vias, traz em sua estrutura conceitual e de fundamentação. Em outros termos, o artigo ressalta os elementos pósestruturalistas que estão presentes na teoria sistêmica de Luhmann, debate teórico este inexistente no Brasil, e ainda pouco debatido no âmbito internacional, excetuando-se trabalhos publicados em língua inglesa e majoritariamente em língua alemã, sobretudo no âmbito do direito.

Artigo recebido em: 31/08/2019

Aprovado em: 22/09/2020
Inicialmente, cabe destacar que o movimento pós-estruturalista, que emerge do estruturalismo desenvolvido na França por Claude Lévi-Strauss, fez vir à tona uma série de reflexóes teórico-filosóficoepistemológicas, no campo da teoria social, a partir da década de 1970, que reconfigurou boa parte da teoria sociológica internacional nos anos 1980. Tais reflexóes orientaram - e ainda orientam, favorável ou contrariamente - muitas das questôes teóricoepistemológicas da sociologia debatidas em alguns dos principais centros internacionais de pesquisa social, tais como: a dimensóes micro e macro da análise sociológica; a necessidade de articulação ente entre sujeito e estrutura; a precariedade e a contingência dos fenômenos sociais; as noçóes de descentramento, desconstrução, desfundamentação, complexidade; e mesmo o caráter pendular de produçóes teóricas que têm oscilado ora em direçáo à agência, ora em direção à estrutura (Archer 2004; Lahire, 2002) ao longo do último quase meio século. 
$\mathrm{O}$ artigo não pretende pôr em relevo se (ou quanto) o pensamento sistêmico-sociológico bebeu nos pressupostos epistemológicos desenvolvidos pelo movimento interdisciplinar pós-estruturalista. É sabido que as origens do desenvolvimento da teoria dos sistemas de Luhmann estão fincadas lá em Talcott Parsons, em seu estrutural-funcionalismo, diversificando, posteriormente, com a incorporação de conceitos oriundos de diferentes áreas do conhecimento científico. O objetivo do texto, nesse aspecto, é demonstrar que os mesmos "ventos" teórico-filosóficos que geraram a crise da metafísica, do humanismo como um dos pilares da teoria sociológica clássica, bem como a crise do determinismo científico, influenciaram a teoria sistêmica de Niklas Luhmann, sobretudo a partir de sua "virada autopoiética", na década de 1980. Assim, ao considerarmos o pós-estruturalismo como uma das tendências de pensamento científico na sociologia, nesse sentido específico, é possível falar em um pós-estruturalismo sistêmico de Luhmann, como pretendemos demonstrar.

$\mathrm{O}$ artigo está estruturado em diferentes momentos para atender aos objetivos principais, quais sejam: expor crítica e reflexivamente a articulação teóricoconceitual da teoria luhmanniana, bem como a radicalidade epistêmico-teórica em sua proposta de uma sociedade "sem" seres humanos, a qual tem gerado contestaçóes, importantes reflexóes e debates na comunidade científica internacional; destacar a centralidade do conceito de comunicação e sua ressignificação (construtivista) para a teoria dos sistemas; apresentar as noçôes de contingência e imprevisibilidade como fortes características de uma matriz pós-estruturalista e pós-fundacional que tem marcado a sociedade contemporânea.

Ao final, é feita a problematização da difícil apreensão teórica e epistemológica do conceito de complexidade - mais precisamente, a ideia de redução de complexidade mediante complexidade. $\mathrm{O}$ artigo adentra em uma reflexão de caráter epistemológico sobre o pós-determinismo, buscando demonstrar que, talvez, indo além do próprio pós-estruturalismo, a teoria dos sistemas sociais de Luhmann indica algumas possibilidades de avanço ao propor esquemas de redução da indeterminação, não alcançado - nem pretendido - pelo próprio pós-estruturalismo.

\section{Em direçáo à radicalidade pós-estruturalista sistêmica luhmanniana: o pós-estruturalismo na sociologia}

Assim como o pós-estruturalismo, conforme nos lembram alguns teóricos do movimento (Huyssen, 1992; Dosse, 1993), abarca um conjunto transdisciplinar de enfoques - por isso nunca fora tomado como uma escola, mas sim como um movimento de pensamento (Dosse, 1993) ${ }^{1}$-, de modo semelhante disciplinas e pesquisadores variados concebem-no, em termos teóricos, por vieses muitas vezes específicos. Diferentemente das abordagens filosóficas como a de Jacques Derrida (1995; Derrida e Caputo, 2009) um dos pavimentadores do caminho percorrido pelo estruturalismo em direção ao pós-estruturalismo, no coração da década de 1960 , dada sua ferrenha crítica à centralidade assumida pela estrutura -, o pós-estruturalismo na sociologia pode ser visto (e tem sido) também de maneira um tanto particular, que não aquela focada quase que exclusivamente na filosófica desconstrução de Derrida.

Um dos grandes problemas teóricos da sociologia, desde suas abordagens clássicas - as perspectivas estruturais (não estruturalistas), em Durkheim; as funcionalistas e todas as suas variáveis, como o estrutural-funcionalismo parsoniano; e, mesmo abordagens micro, como o interacionismo simbólico - é o debate sobre "como o fenômeno social" é possível. Luhmann (2009a), inclusive, questiona: “¿Como es posible el orden social?”. Essa discussão tem sido o fulcro de incontáveis pesquisas teóricas em sociologia. Essa prática científica, no âmbito da disciplina, é claramente visível e ganha relevância a partir da década de 1980, momento em que Jeffrey Alexander (1987) chamou o conjunto de novos esforços teóricos que surgiam em direção à articulação entre açâo e estrutura de "novo movimento teórico". Nesse movimento, identifica-se uma série de esforços teóricos em sociologia, tais como os de Pierre Bourdieu (2000; 2008; Bourdieu e Wacquant, 2005), Anthony Giddens (2003; 2000), Margaret Archer (1988; 2004; 2009) o próprio Alexander (1987), entre outros, que se dedicaram a rearticular a perspectiva teórica da "ação subjetiva" com a perspectiva "objetivista da estrutura". Esse novo movimento teórico de rearticulação de 
subjetividade/objetividade, micro/macro, ação/ estrutura, e que está longe de ser especificamente uma desconstrução, ficou sendo visto (também) como esforços pós-estruturalistas na sociologia, por vezes, inclusive, a contragosto de seus idealizadores.

Assim, em sociologia teórica, debater o pósestruturalismo não significa necessariamente a adoção da matriz desconstrutivista proposta na filosofia de Derrida, que ao mesmo tempo em que ajudou a fazer emergir o pós-estruturalismo, a partir do estruturalismo mesmo, utilizou-o como alavancagem (ou contraponto) à construção e sedimentaçáo de sua filosofia. Lembremos aqui um de seus primeiros textos, "A estrutura, o signo e o jogo no discurso das ciências humanas", de 1966, hoje clássico e um dos mais citados, que deram origem ao pós-estruturalismo e à sua própria filosofia desconstrutivista:

[...] toda a história do conceito de estrutura [...] tem de ser pensada como uma série de substituiçóes de centro para centro, um encadeamento de determinaçốes do centro. O centro recebe, sucessiva e regularmente, formas ou nomes diferentes. Poderse-ia mostrar que todos os nomes do fundamento, do princípio, ou do centro, sempre designaram o invariante de uma presença (eidos, ache, telos, energeia, ousia (essência, existência, substância, sujeito. (Derrida, 1968, p. 103)

Cabe ressaltar que esse "primeiro Derrida", que se inicia por uma crítica filosófica ao cerne do estruturalismo (puro) de Lévi-Strauss (2003; 2003a), não fala claramente em desconstrução, mas da metafísica da presença, ou de um centro. Essa perspectiva, sim, teve uma influência significativa para a articulação entre duas perspectivas que pareciam ser antagônicas (ação e estrutura), na formulação (e avanço) da teoria sociológica. Portanto, os esforços intelectuais específicos que foram realizados para explicar, no âmbito da teorética sociológica, como se dava a articulação entre a dimensão atomística da realidade social (os indivíduos/açóes) e sua dimensão estrutural (as objetivadas instituições sociais) foram vinculados não à desconstrução que não abarca, nem de longe, a totalidade da abordagem pós-estruturalista em sociologia, mas sim à necessária ressignificação de importantes conceitos oriundos das abordagens teórico-epistemológicas mais clássicas; aquilo que Anthony Giddens (1993) chamou "hegemonia do consenso ortodoxo".

Mesmo Urs Stäheli (2006), que tem debatido teórica e filosoficamente o pós-estruturalismo, cremos, não o encerraria táo somente em uma abordagem desconstrutivista, nos termos de Derrida. Vejamos que, ao abordar a noçáo de pós-estruturalismo, Stäheli o faz a partir de duas perspectivas centrais que apontam tanto para a dimensão pós-estruturalista na teoria sistêmica de Luhmann como para a teoria social de um modo geral. A primeira dessas direçôes está no fato de que, para Stäheli, o estruturalismo compartilha "o interesse na geração e na constituição de significado, mas também enfatiza a 'falha' [aspas nossas] necessária de qualquer processo de significação" (2006, p. 453), isto é, não apenas no sentido de um fundamento último, como em Heidegger, mas no sentido mesmo de um fundamento epistemológico. Nos termos da teoria sociológica luhmanniana, o pósestruturalismo sistêmico coloca a dupla contingência como dimensáo operativa do sistema autopoiético que se traduz, de pronto, na permanente impossibilidade de qualquer essencialização da unidade sistêmica. Stäheli ainda acrescenta:

O pós-estruturalismo radicaliza o papel da diferença e, ao fazê-lo, mina certos pressupostos do estruturalismo (...) Primeiro porque o pósestruturalismo é antifundacional, uma vez que a fundação de um sistema (seja Deus, racionalidade, ou uma essência material) perde qualquer posição preestabelecida. (2006, p. 454).

A segunda direção é, com certeza, de cunho marcadamente epistemológico e, em destacada medida, ontológico - uma dimensão onto-epistemológica. Trata-se dos paradoxos que teorias como a dos sistemas autopoiéticos de Luhmann - e também a teoria do Discurso da escola de Essex -, que tomam como ponto de partida a autorreferência, apresentam. ${ }^{2}$ Stäheli (1996, p. 454-5), ao considerar as dimensōes pós-estruturalistas e pós-fundacionalistas, bem como as aproximaçóes conceituais da Teoria do Discurso de Ernesto Laclau e Chantal Mouffe (Laclau e Mouffe, 
1985) com a Teoria dos Sistemas Autorreferentes de Niklas Luhmann, argumenta que:

A figura da autorreferência encontra-se no centro das mais diversas tentativas de descriçóes contemporâneas da teoria da sociedade. A autorreferência fascina, sobretudo, pela sua capacidade de gerar paradoxos (...) Ao contrário do tratamento iluminista dado aos paradoxos, os quais deveriam ser resolvidos da forma mais rápida (...) os paradoxos têm sido vistos, cada vez mais, como potencial criativo, como inegável momento na criação do novo (...) O problema de como a unidade de um sistema pode ser expressa neste mesmo sistema constitui um dos clássicos paradoxos da autorreferência: toda diferenciação, que deva cumprir esta tarefa, é novamente uma diferenciação do sistema a ser representado, o que necessitaria mais uma diferenciação, que representaria a unidade do sistema e sua representação de unidade. Cria-se, por fim, um recurso infinito.

É justamente neste ponto que Stäheli (1996, p. 257) aproxima o pós-estruturalismo em direção à teoria luhmanniana, marcando suas semelhanças teórico-conceituais sociológicas (não filosóficas). Isso fica claramente explicitado ao dizer:

Entretanto, a teoria dos sistemas não pode reclamar de ser a única que trabalha com 'reentries' de paradoxos no discurso da teoria social e cultural. Uma outra linha teórica, à qual foi durante muito tempo negada fertilidade teórica social, a ela faz necessário conceder um papel de precursora quando se orienta segundo uma linearidade cronológica. As mais diversas formas do pós-estruturalismo, principalmente do desconstrutivismo de Derrida, apresentam a produção de estruturas aporéticas em textos e o inevitável fracasso da sua desparadoxização.

Stäheli conclui seu argumento, por um lado, com clara alusão crítica ao pós-estruturalismo filosófico e à desconstrução derridiana e, por outro, ressalta a pertinência provocativa da utilização do pós-estruturalismo tanto na Teoria do Discurso de Laclau e Mouffe como na Teoria Sistêmica de Niklas Luhmann, afirmando o seguinte:

Enquanto estas desconstruçóes ficaram limitadas a textos literários e filosóficos de 'alta cultura', não constituíram uma provocação em relação ao trabalho da teoria da sociedade - muito menos para a teoria sociológica e política. (Stäheli, 1996, p. 258)

Assim, esses diferentes esforços teóricos que foram vistos como o "Novo movimento teórico" abrigaram-se sob a guarda do polissêmico termo pós-estruturalismo, que, na teoria sociológica, implica ressemantização conceitual (sujeito, estrutura, tempo), rearticulação teorética (objetivismo/subjetivismo), descentramento (a desessencialização), construção, reconstrução e também desconstrução. Essas questóes estão muito bem problematizadas, por exemplo, na Teoria da Estruturação de Anthony Giddens (2000; 2003); no construtivismo estruturalista de Pierre Bourdieu (2000; 2007; Bourdieu e Wacquant, 2005); na morfogênese de Margaret Archer (1988; 2004); na Teoria do Discurso de Ernesto Laclau e Chantal Mouffe (Laclau e Mouffe, 1985); e, certamente, na teoria sistêmica de Niklas Luhmann (1998; 2006).

É a partir desse viés que a proposta teórico-sociológica luhmanianna pode - e, na nossa opinião, deve - ser vista na sociologia como pós-estruturalista, isto é, menos pelo aspecto específico de uma observação de diferentes ordens - o que certamente implica desconstrução a la Derrida e também a caracteriza como tal -, mas pelo encadeamento teórico-epistemológico de conceitos tais como sujeito, objeto, ação, estrutura, observação, observador, estrutura e sistema que foram articulados em sua teoria sociológica. É aí também que repousa o que chamamos de radicalidade pós-estruturalista. Novamente, não pela dimensão específica da observação de segunda ordem que, como o próprio Luhmann $(1993$; 2006) afirma, aponta a proximidade (quase filosófica) com a abordagem desconstrucionista derridiana, mas justamente por ter conseguido propor uma superação da dicotomia entre açâo e estrutura de forma dramaticamente radical.

A partir dessas consideraçôes iniciais, para compreendermos a teoria luhmanniana - e sua dimensão 
pós-estruturalista radical - é necessário, primeiramente, considerar-se que o sujeito pesquisador, observador do fenômeno social, tem de realizar um "giro epistemológico" em sua concepçáo tanto de sujeito conhecedor como de objeto conhecido. A base desse giro assenta-se na concepção de uma hermenêutica radical. ${ }^{3}$ Portanto, numa primeira aproximação, esse giro constituiria em observar a sociedade, como fenômeno social, a partir de seu interior, transformando-se, ao mesmo tempo, em sujeito e objeto do conhecimento (nos termos da tradição). Entretanto, na teoria sistêmica luhmanniana, falar em sujeito e em objeto perde completamente o sentido, uma vez que o observador observa (sujeito), auto-observa-se (sujeito-objeto) e é observado (objeto), tudo ao mesmo tempo, numa constante dinâmica de interação sistêmica simultânea de descrições/autodescrições. Isso só é possível, segundo o pensamento sistêmico, porque existem diferentes ordens de observação ( $1^{\mathrm{a}}, 2^{\mathrm{a}}, 3^{\mathrm{a}} \ldots n^{a}$ ordens). Em outros termos, o que a teoria propóe é que a sociedade, como um fenômeno global, é constituída de sociedadessistemas que se auto-observam, se autodescrevem (e se autorreescrevem) como sociedade - não por menos, a última e mais acabada obra de Luhmann chama-se "Die Gesellschaft der Gesellschaft", isto é, "A sociedade da sociedade". A partir disso, a própria relevância de quem observa e de quem é observado, de quem é sujeito e de quem é objeto se perde, posto que a sociedade, segundo Luhmann (1998; 2006), é constituída por fenômenos sistêmicos que observam e se auto-observam através de diferenciações sistêmicas e subsistêmicas, implicando múltiplas ordens de observação, ou seja, a observação do observador que observa... Mais especificamente, a sociedade é um sistema de comunicaçáo composto de subsistemas também de comunicação, incluindo as comunicaçóes individuais - interaçôes entre sistemas psíquicos -, cuja automanutenção depende de contínuos processos (internos) de diferenciação.

Dito de outro modo, pode-se conceber a sociedade mundial como uma totalidade sistêmica que se auto-organiza, se auto-observa e se autodiferencia em unidades subsistêmicas que procedem da mesma maneira, ad infinitum. Luhmann chama isso de evolução da sociedade em direção a um contínuo aumento de complexidade funcional. Também por isso, o autor vê a necessidade de conceber a evolução como história: "É por isto que se impóem a necessidade de se projetar a teoria da evolução como teoria da história" (Luhmann, 2006, p. 331). Assim, ao mesmo tempo em que o sistema observa o entorno (isto é, tudo aquilo que não é ele próprio, incluindo os demais sistemas), ele também observa a si mesmo para, através de processos autorreferidos, "responder" às transformaçōes e perturbaçóes do ambiente, o que desencadeia no sistema social, como um todo, um contínuo processo de subsistematização auto-organizativa, oriunda de interaçóes distintivas que produzem (são produzidas) semânticas. ${ }^{5}$ Tal processo é o que Luhmann (1998; 2006) denominará de redução de complexidade das sociedades contemporâneas, processo que ocorre mediante o aumento de complexidade, como será visto mais detalhadamente adiante.

O ponto de partida adotado por Luhmann (1998; 2009b) ao construir esse modelo teórico é a constatação de que a sociologia, como disciplina científica do conhecimento, passa por uma grave crise teórica. Sob o olhar do sociólogo alemão, um dos principais motivos relacionados a essa crise seria o fato de que tanto a literatura especializada quanto as reunióes acadêmicas realizadas na área, ao redor do mundo, têm como referência fundamental os clássicos da disciplina: Marx, Weber, Simmel e Durkheim. "A impressão que resulta dai é a de que toda a teia conceitual da sociologia esgotou-se com esses nomes"(Luhmann, 2009b, p. 35). O segundo aspecto diretamente vinculado à crise teórica da sociologia seria o apego a um conceito humanistico de sociedade, que tem como referência essencial o ser humano. Para o autor, as teorias sociológicas, em geral, adotam uma postura antropocêntrica, uma vez que partem do pressuposto de que a sociedade é constituída por homens. Nos termos de Luhmann:

Os sistemas da sociedade consistem em comunicaçóes. Não há outros elementos, nenhuma outra substância senão comunicaçóes. A sociedade não é construida por corpos e mentes humanas. Ela é simplesmente redes de comunicações. (Luhmann, 1990, p. 100 [tradução e grifos nossos]) 
Em outra passagem com teor igualmente contundente, Luhmann acrescenta:

Para abordar o tema do presente capítulo é útil recapitular algumas características do quadro teórico desenvolvido até aqui. Estamos tratando de sistemas sociais, não de sistemas psíquicos. Partimos do pressuposto de que sistemas sociais não são constituídos nem por sistemas psíquicos nem muito menos por seres humanos de carne e osso. (Luhmann, 2016, p. 287, [grifos nossos])

Para Luhmann, essa tradição antropocêntrica da teoria sociológica é um grande equívoco epistemológico; primeiro, porque existem bilhóes de pessoas no mundo, cada uma com suas particularidades, então, "o que se quer dizer quando se fala do homem?” (1998, p. 15). Segundo, porque os seres humanos são constituídos, basicamente, por duas dimensôes: uma fisiológica (enzimas, células) e a outra psicológica (consciência, pensamentos), sendo que nenhuma delas, obviamente, pode constituir a unidade de análise da sociologia.

Baseado em tais argumentos, Luhmann defende a ideia de que a sociologia, para explicar de forma coerente a sociedade moderna, necessitaria de um novo modelo teórico, com pretensão universal, capaz de superar os obstáculos epistemológicos que, a seu ver, a teoria sociológica estagnou, isto é, o apego aos autores clássicos, bem como a um conceito humanístico de sociedade.

Ancorado nos avanços teóricos e epistemológicos do pensamento sistêmico desenvolvido ao longo do século XX, de forma interdisciplinar, sobretudo no campo da cibernética, o autor sustenta que há elementos da realidade que apresentam características tais que lhe permitem ser considerados e descritos - no plano teórico - como sistemas. Conforme suas palavras: "Em geral, pode-se falar de sistema quando se tem diante dos olhos caracteristicas tais que, se suprimidas, colocariam em questão o caráter do dito objeto"(Luhmann, 1998, p. 27). Para o autor, é possível afirmar que existem pelo menos quatro tipos de sistemas observáveis no mundo: as máquinas, os organismos vivos, as consciências humanas e a sociedade, como mostra a Figura 1.

$\mathrm{Na}$ teoria luhmanniana, os seres humanos tradicionalmente caracterizados no campo das ciências sociais, por meio de noçôes como ator, agente, sujeito, enfim - são abordados como um tipo específico de sistema formado por pensamentos. Nos processos de interaçấo entre os sistemas de consciências, sáo produzidos incontáveis números de comunicaçôes, as quais constituem os sistemas da sociedade. Ambos os

Figura 1

Níveis de análise da teoria dos sistemas

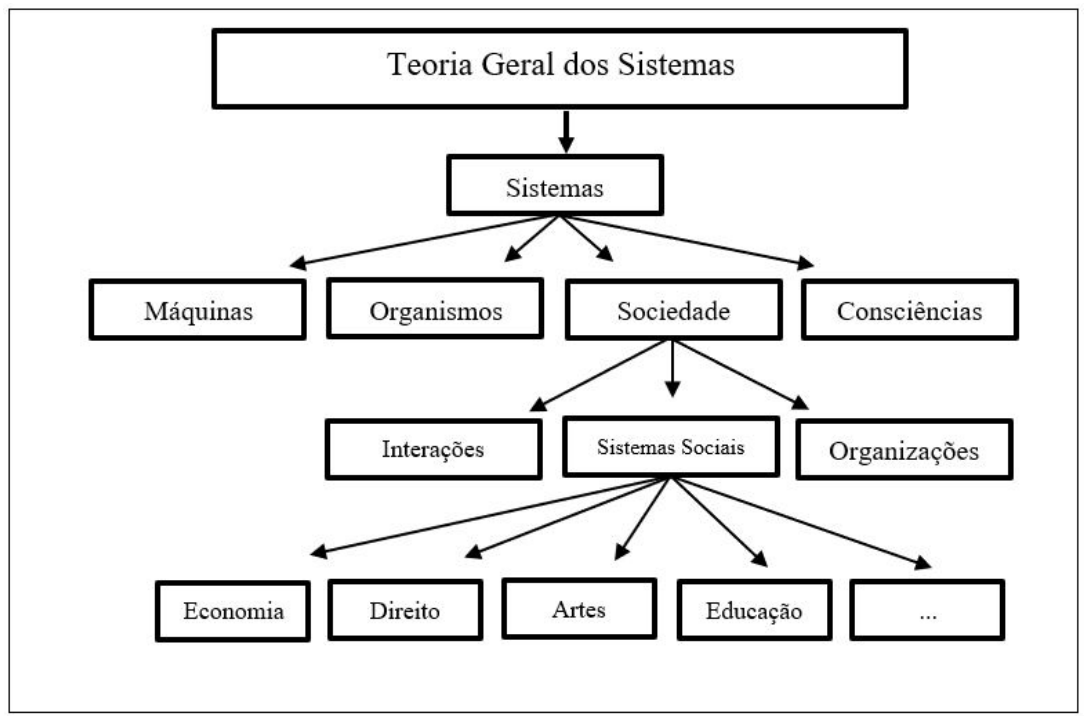

Fonte: elaborado com base em Luhmann (1998). 
sistemas - sociais e de consciência - operam dentro dos seus próprios limites sistêmicos, possuindo relativa autonomia para auto-organizar seus processos internos de forma autorreferente.

Luhmann (2006) defende a teoria de que sistemas sociais e sistemas de consciência nunca se relacionam diretamente - apenas como entorno um do outro. A relação entre sistemas sociais e sistemas psíquicos se dá a partir de acoplamentos estruturais, cujas irritações podem (ou não) vir a influenciar (irritar) a autoprodução de estruturas sistêmicas, isto é, a autopoiésis do sistema. Os indivíduos sabem que se quiserem adquirir um bem precisarão pagar por ele. Assim, a própria ação individual de aquisição gera também uma comunicação sobre o sistema social, no caso, o sistema econômico. Da mesma forma, a sociedade limita e orienta a ação dos sistemas de consciência (bem como dos demais sistemas sociais) através do sistema jurídico. As pessoas, de um modo geral, sabem que não devem cometer determinadas ações (como assaltar ou matar), porque poderão ser severamente punidas.

\section{A sociedade como construtivismo sistêmico comunicacional: radicalizando a dimensão "pós" dos "estruturalismos"}

Luhmann, portanto, adota a noçâo de "sistema” como a unidade analítica de sua teoria. Da mesma forma como Pareto, Parsons e outros autores do campo da teoria sociológica do século XX, o sociólogo alemão defende a ideia de que a sociedade pode ser observada e descrita teoricamente como um sistema. Todavia, o pensamento desenvolvido por Luhmann rompe com toda a tradição teórico-sistêmica das ciências sociais (Rodrigues, 2014; Rodrigues e Neves, 2012; 2017); isso porque, para o autor, o sistema da sociedade não é constituído por pessoas, tampouco por ações, mas exclusivamente por comunicaçóes.

O conceito de comunicação proposto por Luhmann difere, radicalmente, da acepçáo tradicional do termo, em que a comunicação consistiria num processo de transmissão de informaçôes entre interlocutores. Luhmann (2009b, p. 133) afirma que "devemos abandonar a metáfora clássica, segundo a qual a comunicação é uma espécie de transferência de conteúdos semânticos de um sistema psíquico - que já os possui - a outros". A seu ver, a comunicação, antes de tudo, é um acontecimento emergente, que se concretiza mediante a síntese de três seleções: a) seleção do ato de comunicar; b) seleção da informação a ser comunicada; c) seleção que ocorre no ato de entender (ou não) a informação e o ato de comunicar. ${ }^{6}$ "Nenhum desses componentes, de forma isolada, pode constituir a comunicação. Esta só se realiza quando essas três sinteses se efetuam" (Luhmann, 2009b, p. 297). Com efeito, por depender da síntese de três seleçôes, ${ }^{7}$ a comunicação é um acontecimento possível, porém improvável. Ela apenas se probabiliza, em virtude da existência da sociedade, a qual estabelece estruturas simbólicas que tornam possível a comunicação entre Alter e Ego. "Somente através dessas estruturas a improbabilidade da comunicação se transforma em probabilidade” (Luhmann, 2006, p. 177-8). É desse modo que, para Luhmann, se dá a redução da complexidade da totalidade do sistema da sociedade.

No decurso da vida social, as comunicaçóes - mesmo que sejam improváveis, como defende Luhmann (2006) - podem conectar-se umas às outras, levando a processos de formação (funcionalestruturalistas) de sistemas sociais, como educação, política, ciência, arte etc. Como destaca Stichweh (2012), a conectividade sequencial de infinito número de comunicaçóes parciais leva aos processos de formação de sistemas. A própria sociedade não é outra coisa senão a construção, desconstrução e reconstrução - num processo incessante - de um gigantesco sistema que engloba todas as comunicações possíveis e seus diferenciados e contingentes subsistemas comunicativos, com suas funcionalidades específicas, mesmo que sempre precárias, do ponto de vista das interaçóes relacionais.

Luhmann rompe com a tradição teóricosistêmica das ciências sociais não apenas ao adotar a comunicação como elemento constitutivo dos sistemas da sociedade, mas também ao defender o princípio de que esses sistemas são autorreferentes (Rodrigues e Neves, 2012; 2017). Segundo o autor, "há sistemas que têm a capacidade de estabelecer relaçóes consigo mesmos, e de diferenciar essas relaçóes ante seu entorno" (Luhmann, 1998, p. 38). Sistemas autorreferentes, em outras palavras, são aqueles que conseguem, eles 
mesmos, estabelecer limites de sentido que norteiam a estruturação da operacionalidade funcional. Isso porque a autorreferência não diz respeito à comunicação, mas sim ao sentido dessa comunicação.

"Disto, resulta que a autorreferência acontece como um modo de comportamento em um entorno que não está estruturado ao seu gosto e que náo se pode submeter ao desejo"(Luhmann, 1998, p. 38).

A tese defendida por Luhmann ainda vai além, ao sustentar que a autorreferência, habilidade característica dos sistemas sociais, é de um tipo muito específico: é autopoiética. Como destacam Rodrigues e Neves (2012, p. 30), "a noção de autopoiésis associada à ideia de autorreferência tem se constituido na inovação contemporânea mais importante da teoria sistêmica desenvolvida no século XX”. Essa noção foi proposta na década de 1970, pelo biólogo chileno Humberto Maturana. O termo é oriundo da junção das palavras gregas auto (si mesmo) e poiesis (produção), indicando um organismo que possui a capacidade de produzir a si próprio, diferenciando-se de seu entorno. Ao formular essa noção, Maturana buscava responder a uma das grandes questóes da ciência: a origem da vida. Segundo sua própria definição:

uma máquina autopoiética continuamente é específica e produz sua própria organização através da produção de seus próprios componentes sob condiçôes de contínua perturbação e compensação dessas perturbaçóes. Podemos dizer entáo que uma máquina autopoiética é um sistema homeostático que tem a sua própria organização. (Maturana e Varela, 1997, p. 71) [grifos dos autores]

Segundo essa definição, um sistema autopoiético é aquele capaz de produzir, desde si mesmo, os componentes internos que o constituem como unidade, além de estabelecer as conexóes entre esses componentes, em um contexto de contínuas perturbaçóes e compensação dessas perturbaçóes. Em outros termos, considerandose um contínuo processo probabilístico sistêmico de manutenção funcional-estrutural, que implica autoprodução de ordem/desordem - é importante frisar que tais processos ocorrem a partir do ponto de vista do observador, posto que do ponto de vista do sistema, como unidade autopoiética, ele visa sempre à sua homeostase (equilíbrio) com o meio -, tanto uma perspectiva de ordem quanto de mudança e de manutenção (autoteleologia) não provêm de qualquer causa externa (relaçáo linear de causa e efeito), mas sempre de processos interativos de autocausação. Um sistema autopoiético, portanto, é uma unidade homeostática, que consegue se manter em relativo estágio de equilíbrio sistêmico, apresentando um determinado padrão de funcionamento e uma relativa autonomia ante seu entorno. ${ }^{8}$ Isso explicaria, por um lado, a questão da ordem social e, por outro, a questão de sua mudança, dadas as contingências auto-organizativas de cada sistema e subsistema e da relativa instabilidade do todo.

Ao desenvolver a noção de autopoiésis, Humberto Maturana tinha em mente os organismos vivos. Luhmann, no entanto, ciente da riqueza teóricoepistemológica desse conceito, percebeu que ele poderia ser aplicado à análise do social. Entretanto, Luhmann (1998) deixa claro que não está realizando uma mera analogia, ou transposição epistemológica de um conceito desenvolvido no seio da biologia para a sociologia. Ele argumenta que, assim como os sistemas orgânicos são autopoiéticos, existem outras classes de sistemas, como os psíquicos e os sociais, que também apresentam as mesmas características descritas pela noção de autopoiésis. Segundo o sociólogo alemão, os sistemas da sociedade, para se autoproduzirem e reproduzirem autopoieticamente, fazem-no através das comunicaçóes. As comunicaçóes que formam a sociedade, defende Luhmann, se reproduzem de maneira recursiva. Isso significa dizer, que a sociedade produz a si mesma de maneira autorreferente. Conforme as palavras do autor:

A comunicação se torna provável por si mesma e não pode efetuar-se como acontecimento isolado. Toda comunicação supóe comunicações - estimuladas por ela mesma e ante as quais se reage - de seu mesmo tipo. Sem uma referência recursiva deste gênero, não haveria nenhum motivo para a comunicação acontecer. (Luhmann, 2006, p. 145)

Para que essa ideia fique clara, devemos ter em mente, por um lado, que a sociedade é formada por 
uma rede infinita de comunicaçóes parciais conectadas umas às outras; por outro lado, devemos considerar também que a sociedade é a condição de possibilidade de cada uma dessas comunicações. Com efeito, não há comunicação que exista fora dos limites da sociedade, sendo que todo evento comunicativo passa a integrar a rede de comunicaçóes que constituem essa sociedade. Através da reprodução recursiva de comunicaçóes, a sociedade demarca uma diferença de sistema/entorno, primeiro, em relação àquilo que é social (comunicação) e o que não é; segundo, em relação a ela própria, ou seja, ao seu interior, ao se diferenciar em ambientes internos, quer dizer, em sistemas e subsistemas parciais, os quais são entorno um do outro.

\section{O pós-estruturalismo sistêmico de Luhmann ante as questóes: ação versus estrutura, centramento/descentramento, construção/ desconstrução, certeza/contingência}

O fim da ilusão quanto à possibilidade de ancoragem em um fundamento último da teoria social contemporânea pode ter como um referente importante a crise do estruturalismo francês - lembremos que Lévi-Strauss (1970; 2003) acreditava ter encontrado as leis determinísticas da base cultural de diferentes sociedades, a partir do método estruturalista oriundo da linguística. Dizia ele: "A Fonologia não pode deixar de desempenhar, perante as Ciências Sociais, o mesmo papel renovador que a física nuclear, por exemplo, desempenhou no conjunto das ciências exatas"(1970, p. 49). A crise desse estruturalismo mais "duro", sobretudo no que tange à abordagem levi-straussiana, emergiu a partir do final da década de 1960, tendo como origem os trabalhos desenvolvidos por autores tais como Derrida, Deleuze, Lyotard, Barthes, Foucault e Kristeva, entre outros, que vislumbraram a impossibilidade de um centro fundante.

O pós-estruturalismo na teoria social, em especial na teoria sociológica, não pode ser visto apenas como a proposta (mais filosófica que científica) centrada no desconstrutivismo de Jacques Derrida, ou na multiplicidade dos platôs de Deleuze e Guattari. O movimento que se chama de pós-estruturalista e que propositadamente borra as fronteiras entre filosofia, ciência e literatura influenciou, de forma muito mais abrangente, o pensamento teórico sociológico, servindo de gatilho, ou mesmo de inspiração, a diferentes vertentes da pesquisa teórica nas ciências sociais. Foi a partir do pós-estruturalismo que distintos teóricos, tais como Pierre Bourdieu (1980; 2000) - com seu "estruturalismo construtivista" - e Anthony Giddens (2003) - com sua "dualidade da estrutura" -, passaram, por exemplo, a resgatar um sujeito - morto por Foucault em sua fase marcadamente estruturalista. $\mathrm{O}$ pós-estruturalismo também parametrizou teorias no âmbito da ciência política, como a obra autodeclarada pós-marxista e pós-estruturalista de Ernesto Laclau e Chantal Mouffe (Laclau e Mouffe, 1985); as teses pós-fundacionalistas de Oliver Marchart (2007); e as abordagens epistemológicas de Jason Glynos e David Howarth (Glynos e Howarth, 2007), para citar apenas alguns.

Equivocam-se aqueles que assumem que o pósestruturalismo é uma forma de pensar anterior ou posterior àquilo que conhecemos como estrutura na teoria social, ou ainda que toda a dimensão estrutural dos fenômenos sociais está superada. O que o pósestruturalismo - como movimento teórico e filosófico - reivindica é o deslocamento da estrutura da posição central que a colocara o estruturalismo, sobretudo a abordagem de Lévi-Strauss, a qual propôs formas invariantes universais, sincrônicas e trans-históricas. Essa é a pedra de toque da crítica (filosófica) derridiana ao movimento estruturalista.

Para Derrida, ao contrário da lógica fundante estruturalista, uma estrutura não possui qualquer significado transcendental e, por esta razão, o jogo da significação não tem propriamente limite. Dessa forma, a estrutura é descentrada, sendo esta ideia "um abandono declarado de toda referência a um centro, a um sujeito, a uma referência privilegiada, a uma origem ou a uma arquia absoluta”. A crítica derridiana ao centro como fundamento da estrutura desnuda o limite de significação desta, pondo-o em xeque. Se não há um princípio transcendental fora de todo o jogo das diferenças, se esse centro é também parte da articulação, abre-se outra perspectiva 
epistemológica (e também ontológica) a partir do próprio estruturalismo. (Mendonça e Rodrigues, 2014b, p. 41)

Derrida, desde muito cedo, apontou para o fato de que o estruturalismo de Lévi-Strauss, que transpóe o fundamento epistemológico da linguística moderna de Saussure, isto é, a relação entre significante e significado, para o seio das ciências sociais, propiciou uma teoria radicalizada da diferença. Conforme mencionam Mendonça e Rodrigues (2014b, p. 41-2), Derrida, mesmo antes de se tornar conhecido "como o 'filósofo da desconstrução', em seu agora clássico texto de 1966, 'A estrutura, o signo e o jogo no discurso das Ciências Humanas', '’ já criticava a necessidade de um centro fundante, onde observador e observado detinham assentos epistemológicos marcados". Nos seus termos:

O centro recebe sucessivamente, e de maneira regular, formas ou normas diferentes. A história da metafísica, tal como a história do Ocidente, seria a história dessas metáforas e metonímias. A sua forma matricial seria (...) a determinaçáo do ser como presença em todos os sentidos desta palavra. Poder-se-ia mostrar que todos os nomes do fundamento do princípio ou do centro designaram sempre a invariante de uma presença (eidos, arché, telos, energia, ousia) (essência, existência, substância, sujeito) aletheia (transcendentalidade, consciência, Deus, homem etc.). (Derrida, 1968 p. 103 [grifos do autor])

Como bem indicou Peters (2000, p. 37), "o pensamento pós-estruturalista desenvolveu, dentro de lógicas próprias, uma série de diferentes métodos e abordagens teóricas" voltadas para privilegiar noçōes, tais como: diferença, descontinuidade, ruptura, indeterminação, desessencialismo, deslocamento, desconstrução, contingência, precariedade e complexidade. Por certo que o arcabouço conceitual luhmanniano assume boa parte da reflexão pós-estruturalista, funcionando, também, "dentro de sua lógica própria", como bem mencionou Peters. Embora, como se abordará a seguir, o pós-estruturalismo sistêmico de Luhmann tenha sido explorado a partir da filosofia da desconstrução derridiana - originada no seio do movimento pós-estruturalista -, o pós-estruturalismo luhmanniano, seguindo uma das primeiras trilhas do pós-estruturalismo decalcado na teoria sociológica, imprime inegáveis esforços para superar os dilemas do debate "açáo versus estrutura", abordagem "micro versus macro", que até o final do movimento estruturalista eram irreconciliáveis.

A teoria luhmanniana estabeleceu um diálogo com o pós-estruturalismo - inicialmente com o debate pósmoderno, vale destacar - ainda na década de 1990, como bem mencionou Hans-Georg Moeller (2006). Entretanto, e aos poucos, o debate foi se voltando mais especificamente para a desconstrução derridiana - sobretudo no âmbito da teoria do Direito e menos pela teoria sociológica. Para Moeller, Luhmann, assim como Derrida, é um teórico da diferenciação, e não da identificação. Tanto o é que, logo na introdução de Social systems (a qual aponta em direção a uma mudança de paradigma na teoria dos sistemas sociais), Luhmann (1998, p. 34) deixa claro o seguinte: "Se oferece aqui a diferença entre identidade e diferença". O autor ainda completa com uma nota de rodapé: "Quem ler com atenção [este livro], se dará conta de que se está falando da diferença entre identidade e diferença, e não da identidade entre identidade e diferença Igrifos no original]". Gunther Teubner (2008), por sua vez, salienta que Luhmann e Derrida fizeram o mesmo diagnóstico sombrio da era moderna: onde muitos analistas observam decisóes legais e econômicas adotadas racionalmente com base em cálculos lógicos de custo/benefício, o sociólogo alemão e o filósofo francês observam decisóes que apresentam componentes de loucura, irracionalidade e mistério. A irracionalidade, argumenta Teubner $(2008$, p. 2), não é um mero componente negligenciável da decisão, mas, antes, seu aspecto central, de maneira que tanto para Luhmann quanto para Derrida "a arbitrariedade, as inconsistências, as antinomias, os paradoxos e até mesmo a violência estão na base dos construtos mais refinados da ação econômica e jurídica".

Não se pode esquecer ainda que, em 1993, Luhmann publicou um artigo intitulado Deconstruction as Second-Orderobserving, na revista New Literary History. Nesse texto, o autor argumenta que a desconstruçáo proposta por Derrida - para além do equivocado uso 
político-estratégico em que normalmente é empregada - chama a atenção para o fato de que as diferenças são apenas distinçóes, cujos valores de uso se alteram em diferentes momentos e contextos. A diferença entre homossexuais e heterossexuais, por exemplo, afirma o autor, nem sempre é a mesma. Luhmann (1993, p. 764) não faz objeção ao argumento derridiano, mas apenas questiona: "Quem (isto é, que sistema) está usando a distinção como um quadro (ou esquema) de observaçóes; ou, quem é o observador?".

Em outras palavras, o que Luhmann questiona é que, se aceitamos que as diferenças são apenas distinçóes que separam determinadas identidades, tais como heterossexuais/ homossexuais, negros/ brancos, homens/ mulheres, enfim, não podemos nunca esquecer que tais distinçóes só existem aos olhos de um observador, dentro de um dado contexto de observação. O que faz a desconstrução, então, é mostrar como essas distinçóes são semanticamente mobilizadas no contexto da observação. Justamente por isso é que Luhmann dirá que a desconstrução é como uma observação de segunda ordem, isto é, uma observação de observadores. É importante destacar, inicialmente, que no âmbito da teoria dos sistemas, observar é uma operação que ocorre no interior de um dado contexto comunicativo dotado de sentido, através da qual um observador traça esquemas de diferenciação que lhe permitem identificar (distinguir) determinados elementos da realidade (Arnold, 2004). Nesse aspecto, um observador de segunda ordem é uma espécie de observador "externo", capaz de observar a forma pela qual outros observadores observam o mundo (Luhmann, 2006; Arnold, 2004). A partir de sua posição, um observador de segunda ordem consegue vislumbrar, simultaneamente, aquilo que o observador de primeira ordem vê, e o modo como vê. Em outras palavras, a observação de segunda ordem possibilita identificar os esquemas de distinção usados pelo observador de primeira ordem ao observar o mundo.

A observação de segunda ordem é um dos conceitos-chave da teoria sistêmica luhmanniana, sendo justamente um dos principais pontos de aproximação entre o pensamento do autor e o pósestruturalismo, em especial, no que tange à filosofia de Derrida. Para clarificar a obscuridade desse conceito que é altamente abstrato, Luhmann (1993), em seu já referido artigo, toma como exemplo um debate travado em torno da proibição de homossexuais no serviço militar dos Estados Unidos ocorrido no início dos anos 1990. Tal debate envolveu diferentes observadores: oficiais do Exército, políticos, integrantes da sociedade civil, ativistas dos movimentos LGBT etc. Segundo Luhmann, a estereotipicidade da distinção heterossexuais/homossexuais faz parecer que todos esses observadores se referem ao mesmo objeto, o que é uma ilusão. Dentro de suas particularidades, cada um desses observadores acredita piamente na existência de uma rígida relação entre observação/ realidade do objeto, isto é, eles creem que suas observaçóes refletem aquilo que o objeto de fato o é. Todavia, um observador de segunda ordem logo veria que o que existe, na verdade, é apenas um observador de primeira ordem tecendo afirmaçóes parciais com base em uma relação muito frágil entre observação/ objeto observado.

Nesse sentido, o que o observador de segunda ordem faz é desconstruir a observação de primeira ordem, apontando sua parcialidade, destacando os esquemas de diferenciação usados pelo observador de primeira ordem. E aqui nos deparamos com um grande paradoxo: a observação de segunda ordem é também uma observação parcial da realidade, à medida que toda observação (seja ela de primeira ou de segunda ordem) é uma operação através da qual um observador traça esquemas de distinção. O resultado desse paradoxo é o fato de que toda observação passa a ser vista como uma observação parcial que não reflete nada mais do que as distinçóes traçadas pelo observador, quer dizer, apenas aquilo que o observador viu desde sua posição parcial.

Para Luhmann (1993), cada observador opera dentro de seus limites de sentido, possuindo um passado e um futuro particular. Da mesma forma, cada observador está inserido também em um dado contexto de observação dotado de sentido que condiciona a observação - o Exército e a academia, por exemplo, certamente são contextos muito distintos no que tange à observação da diferença entre heterossexuais/ homossexuais. O que a desconstrução faz - e por isso ela se aproxima da observação de segunda ordem, segundo Luhmann - é revelar que toda observação 
é parcial, de maneira que não há nem observação nem observador absolutos. A desconstrução, assim como a observação de segunda ordem, argumenta Luhmann, destrói a suposição de que há uma única observação, de que há um único mundo observável. A desconstrução destrói identidades e fundamentos que até pouco tempo eram vistos como estáveis e incontestáveis, como a heterossexualidade, revelando quão frágeis e autoenganosos podem ser. A proibição de homossexuais dentro das Forças Armadas, nesse sentido, e também de mulheres, muito mais do que uma mera hipocrisia da sociedade, reflete uma retórica cega de autoenganação que visa sustentar uma identidade que, de tão frágil, não se sustenta: a de que para ser um soldado é preciso ser um homem heterossexual. E o que há em particular na desconstrução é que ela revela essa fragilidade das identidades, sem, no entanto, ter a pretensão de recuperar uma unidade posterior ou superior.

A desconstrução derridiana, portanto, aproxima-se de uma operação, tal como a observação de segunda ordem luhmanniana (mas sem o sê-lo de forma propriamente dita, deve-se advertir). O próprio Derrida $^{10}$, em uma de suas cartas endereçadas a seu colega japonês Toshihiko Izutsu, afirma que escolheu o termo "desconstrução" - derivado da palavra alemã "Destruktion", proposta por Heidegger - em virtude de seus significados linguísticos e gramaticais estarem associados a um sentido "mecânico", ou seja, ao ato de desconstruir alguma coisa. A desconstrução sustenta Luhmann, apropriando-se de uma fala de Humberto Maturana - revela que tudo o que é dito é dito por um observador. Ou, em outras palavras, que tudo aquilo que é dito pode ser desconstruído. $\mathrm{Ou}$, ainda, que todo fundamento, toda identidade, é desconstruível. O resultado dessa interpretação não poderia ser outro: um mundo pós-fundacional, que não possui um centro, uma verdade, ou uma identidade absolutos, mas, antes, uma incontável diversidade de centros, verdades e identidades.

A filosofia pós-estruturalista de Derrida e a teoria sistêmica de Luhmann, com efeito, para além de suas particularidades teórico-epistemológicas que aparentemente as tornam constructos muito distantes um do outro, aproximam-se pelo fato de conceberem o mundo náo como uma totalidade centrada, um espaço onde imperam certezas e verdades; pelo contrário, para ambos os autores, o mundo é um espaço aberto, policêntrico, contingente, no qual cada verdade é uma verdade parcial, construída com base na perspectiva de um observador limitado pelas suas possibilidades de operaçóes internas (descritas por outros observadores), bem como pelas condiçóes externas do contexto de observação. Ambos os pensamentos adotam uma radicalidade, da qual eles próprios não escapam: ao sustentar que toda observação é uma observação parcial, Luhmann aceita que seu modelo teórico não está acima de nenhum outro e nunca chegará próximo de esgotar as possibilidades de sentido do objeto; Derrida ${ }^{11}$, por sua vez, também reconhece que a própria ideia de desconstrução pode ser desconstruída, advindo justamente daí a dificuldade em definir precisamente o conceito - vale lembrar que o filósofo francês chega a fazer a seguinte afirmação: "O que a desconstrução não é? Tudo, é claro! E o que é desconstrução? Nada, claro?’.

\section{O pós-estruturalismo sistêmico também como afrontamento à complexidade}

O debate pós-estruturalista não traz explicitamente - sobretudo a partir de uma perspectiva epistemológica - uma discussão sobre a complexidade. O estruturalismo e, mais ainda, o pós-estruturalismo não tiveram a pretensão de se constituírem em escola de pensamento. O pós-estruturalismo, que emerge do próprio interior do estruturalismo, é, antes, um movimento de pensamento que tem em comum com seu predecessor algumas intuiçóes, tais como: a rejeição à ideia de origem; a crítica à autonomia do sujeito; a valorização do discurso em sua materialidade; a compreensão de que a linguagem possui uma ordem própria; a noção de signo como algo que se oferece à interpretação etc. Acertadamente, Jonathan Culler (1997, p. 27) destacou que "os pós-estruturalistas afirmam saber apenas das impossibilidades [do] conhecimento". Entretanto, um traço que certamente perpassa todos os diferentes esforços pós-estruturalistas, constituindo-se num ponto nodal, é o reconhecimento da crise do determinismo, ou seja, o pós-estruturalismo, quando olhado de uma perspectiva epistemológica, constitui-se num pós-determinismo. 
É justamente aí que a teoria sistêmica autopoiética luhmanniana não apenas conflui em direção ao movimento pós-estruturalista, como também se propóe a avançar, indicando possibilidades para a redução da indeterminação e, consequentemente, da complexidade. Segundo Luhmann (2006, p. 100), a complexidade "representa o problema central da teoria dos sistemas".

$\mathrm{O}$ autor a vê como

uma medida de indeterminação ou a carência de informação, [...] como aquela informação que faz falta ao sistema para poder apreender com justeza seu entorno (complexidade do entorno) e a si mesmo (complexidade do sistema). (1998, p. 50 [grifos nossos])

Para Luhmann, a complexidade é "necessidade de seleção". Posta dessa maneira, o autor propóe um novo olhar para a complexidade, problematizando até que ponto se pode falar em diferença, gradiente e redução de complexidade. Entretanto, afirma que é possível redução de complexidade quando "o complexo de relaçóes de um entremeado complexo é reconstruido mediante um segundo entremeado de relaçóes menores" (1998, p. 50). Tal argumento favorece o entendimento da dificultosa noção luhmanniana de "redução da complexidade mediante complexidade", uma vez que, para Luhmann, a complexidade só pode ser enfrentada (ou reduzida) pela própria complexidade constituindo-se esse argumento em um de seus tantos paradoxos. Acrescenta ele: "Este pode ser o caso tanto para a relaçáo exterior do sistema como para a relaçáo interior do sistema consigo mesmo" (1998, p. 49).

A partir dessa perspectiva, parece estar claro que a complexidade se refere, necessariamente, à relacionalidade simultânea existente entre elementos de um dado sistema e entre sistemas no entorno. Essa relacionalidade, de certo modo, sempre esteve como uma "presença-ausente" ou em latência nas abordagens pós-estruturalistas da maioria de seus pensadores. Da mesma forma, tal relacionalidade sempre apontou para a noção de complexidade, entretanto, o pós-estruturalismo, em momento algum, propôs uma epistemologia (ou uma teoria) para seu afrontamento. As abordagens pós-estruturalistas, em suas diferentes matizes, quando falam sobre complexidade, o fazem por um viés de negatividade (no sentido filosófico), ou seja, a impossibilidade de estabilidade, fixidez, invariabilidade, inextinguibilidade, determinação, substância, essência, ou mesmo no sentido do contínuo "desencapsulamento" derridiado (Derrida e Caputo, 2009). O pós-estruturalismo presente na teoria sociológica de Niklas Luhmann - aqui também considerado pós-estruturalismo sistêmico ou autopoiético - explora a possibilidade de afrontamento, por meio da noção de redução de complexidade, mesmo tendo de expor e enfrentar a desparadoxização de determinados paradoxos.

Não podemos perder de vista, por fim, que na teoria luhmanniana a complexidade está diretamente vinculada à relação que o sistema mantém com seu entorno. Isso porque todo sistema só existe como uma unidade acoplada a um ambiente, o qual é infinitamente maior e mais complexo que o sistema. Portanto, cada sistema é sempre uma unidade redutora de complexidade. Justamente daí é que se situa uma distinção - e o avanço mencionado - entre a teoria luhmanniana e o pós-estruturalismo, o qual, em suas diferentes versões, sobretudo as de origem francesa, assume a indeterminação quase que por completa sendo o exemplo mais cabal a teoria dos signos de Derrida. Para Luhmann, com efeito, são também infinitos os estímulos do meio que perturbam a reprodução do sistema. Consequentemente, “o sistema requer o desenvolvimento de uma disposiçáo especial para a complexidade, no sentido de ignorar, rechaçar, criar indiferenças, enclausurar-se em si mesmo" (Luhmann, 2009a, p. 179). Isso significa dizer que o sistema, como unidade limitada, não consegue reagir, ponto a ponto, a todos os estímulos do meio. O sistema seleciona apenas alguns desses estímulos (comunicaçôes), ignorando outros tantos, para justamente proceder à redução de complexidade.

Para a teoria dos sistemas sociais, o mundo é o ponto máximo de referência de complexidade, uma vez que engloba todas as possibilidades de interaçáo, comportamento, acontecimento e comunicação etc. Os seres humanos, como sistemas de consciência, não estáo capacitados para lidar cognitivamente com o alto grau de complexidade do mundo. Assim, "entre a extrema complexidade do mundo e a consciência humana existe uma lacuna. E é neste ponto que os 
sistemas sociais assumem a sua função. Eles assumem a tarefa de redução de complexidade" (Neves; Neves, 2006, p. 192).

A sociedade, como macrossistema constituído por todas as comunicaçóes possíveis, tem como sua tarefa reduzir a complexidade do mundo. Ela o faz por meio do estabelecimento de estruturas simbólicas, as quais reduzem e organizam as possibilidades de ação e comportamento, orientando, assim, as açóes humanas no tempo-espaço. Em outras palavras, a redução de complexidade realizada pela sociedade é o que garante a reprodução da vida social. É nesse ponto que a teoria dos sistemas sociais se depara com um problema intransponível: redução de complexidade envolve, necessariamente, aumento de complexidade. Isso porque, para que um sistema possa reduzir a complexidade do ambiente, ele precisa aumentar sua complexidade interna, ou seja, tem de (re)organizar suas estruturas e as relaçóes entre estas, estabelecendo novos ambientes internos que, por sua vez, podem ser observados como sistemas parciais ou subsistemas. É justamente esse processo que caracteriza a formaçáo da sociedade moderna, a qual se encontra diferenciada em um incontável número de sistemas e subsistemas funcionais.

É importante destacar, nesse sentido, que no último século a sociedade moderna passou por uma inflação populacional drástica, aumentando de 978 milhões de habitantes, em 1800, para 7,6 bilhóes, atualmente. Soma-se a essa maciça expansão populacional a emergência de novas ferramentas de comunicaçáo em massa, que aumentaram sobremaneira o grau de conectividade das relaçóes humanas. Nunca antes na história os seres humanos estiveram táo conectados em escala mundial, e eventos locais tâo vinculados a acontecimentos globais (Castells, 2003; Giddens, 1990).

Com efeito, à medida que aumentaram de forma exponencial as comunicaçóes humanas e as possibilidades de conexão entre elas, expandiu-se radicalmente a complexidade do mundo. Para lidar com essa complexidade ascendente, a sociedade moderna enfrentou um radical processo de diferenciação, o qual envolveu a criaçáo de ambientes internos, isto é, sistemas funcionais, cada um responsável por desempenhar uma tarefa específica para a manutenção do funcionamento do todo social. Esse processo, através do qual um sistema se subdivide internamente em sistemas parciais, visando reduzir a complexidade do meio, Luhmann denomina de diferenciação funcional. Conforme suas palavras, a diferenciaçăo funcional

não é outra coisa que uma construção recursiva do sistema, a aplicação da construçáo sistêmica a seu próprio resultado. Com esta, o sistema dentro do qual se formam outros sistemas se reconstrói através de uma ulterior distinção entre sistema parcial e entorno (Luhmann, 2006, p. 473).

Não apenas a sociedade moderna está organizada em torno de sistemas parciais, como também cada um desses sistemas possui seus próprios ambientes internos. No caso do sistema da ciência, por exemplo, a diferenciação funcional aconteceu devido a um vasto processo de disciplinarização do conhecimento, por meio do qual surgiram incontáveis disciplinas. ${ }^{12}$ Assim, áreas como física, química e sociologia podem ser vistas como sistemas parciais que integram o sistema científico; tais disciplinas, por sua vez, possuem ainda suas próprias divisóes internas: sociologia da ciência, do trabalho, da educação; física nuclear, dos materiais, astrofísica; química orgânica e inorgânica. É importante frisar que a diferenciação funcional ocorre sempre como uma tentativa do sistema no sentido de reduzir a complexidade do entorno (o que acaba implicando o aumento da complexidade interna do sistema), sendo também um processo que se dá de maneira recursiva, ou seja, um sistema cria seus ambientes parciais tendo como referência sempre a si próprio.

\section{Consideraçóes}

Neste artigo, procurou-se discutir os aportes teóricos e epistemológicos que não apenas apresentam os complexos meandros da teoria luhmanniana, mas também as congruências com o pós-estruturalismo e os avanços para além desse movimento. Foram expostos, assim, os conceitos fundamentais da teoria dos sistemas sociais autopoiéticos de Luhmann, bem como uma reflexão sobre as principais noçōes do pós-estruturalismo. Isso permitiu que se realizasse 
uma abordagem, de certo modo comparativa, entre a teoria sistêmica e o pós-estruturalismo, assumindo que a perspectiva luhmanniana se harmoniza com esse movimento de pensamento. De um modo geral, buscou-se demonstrar que a teoria desenvolvida por Luhmann está ancorada em pressupostos epistemológicos muito semelhantes àqueles do pós-estruturalismo, quais sejam.

a) A sociedade é um gigantesco sistema que engloba todas as comunicaçóes possíveis, quer dizer, tudo aquilo que é social. $\mathrm{O}$ que não é comunicação não faz parte do sistema da sociedade, estando, portanto, em seu entorno - inclusive os seres humanos. Consequentemente, a sociedade não pode ser descrita em termos antropológicos, tampouco psicológicos;

b) A sociedade tem como uma de suas principais características a autopoiésis, isto é, a capacidade de produzir, desde si mesma, os elementos que a constituem (as comunicaçóes) como sistema, bem como de estabelecer a relação entre eles. Nesse processo, o sistema da sociedade demarca os limites em que opera, distinguindo-se de seu entorno;

c) A tarefa da sociedade consiste em reduzir a complexidade do mundo, isto é, reduzir a um número limitado de alternativas as infinitas possibilidades de ação e de vivência que estão à disposição dos sistemas psíquicos. Para desempenhar essa função, a sociedade se encontra diferenciada funcionalmente em uma ampla variedade de sistemas e subsistemas sociais, cada um responsável por realizar uma função específica que contribui para o funcionamento do todo social;

d) A indeterminação (ausência de um fundamento determinante) constitui-se num traço marcante nos diferentes esforços pós-estruturalistas. A teoria luhmanniana, por seu caráter epistemológico, se insere numa dimensão pós-determinista, ao assumir a crise do determinismo científico, e também ao reconhecer a ausência de um centro controlador do social. Entretanto, diferentemente do pós-estruturalismo, propóe medidas de redução da complexidade, para os diferentes sistemas sociais. É justamente aí que a teoria sistêmica autopoiética luhmanniana não apenas conflui em direção ao movimento pós-estruturalista, como também se propóe a avançar, indicando possibilidades para a redução da indeterminação e, consequentemente, da complexidade.

Por fim, cabe destacar que a teoria de Niklas Luhmann tem sido cada vez mais estudada no Brasil. Todavia, a divulgação desse modelo teórico no meio acadêmico nacional ainda é bastante tímida. Se esse modelo já está consagrado em diferentes países da Europa, nos Estados Unidos, México e Chile - para mencionar apenas alguns locais -, no Brasil, no entanto, apenas muito recentemente é que algumas de suas principais obras começaram a ser traduzidas. Ainda são escassas as reflexóes teóricas e a pesquisa em torno dessa ampla, abstrata e complexa reflexão sobre a sociedade. Este artigo, justamente, procurou ajudar a suprir essa lacuna.

\section{Notas}

1 Segundo Dosse (1993, p. 203), o ano de 1959 é a ocasião de dois encontros importantes: no primeiro, Roger Bastide organiza um grande colóquio em janeiro em torno da noção de estrutura; no segundo, Maurice de Gandillac, Lucien Goldmann e Jean Piaget presidem o colóquio de Cerisy em torno do confronto entre gênese e estrutura. O encontro organizado por Bastide (1971) foi publicado no Brasil, em 1971, pela Editora da USP. No volume, encontram-se trabalhos interdisciplinares de diversos pesquisadores vistos, mais tarde, muitos deles, como estruturalistas.

2 Em 2004 tivemos a oportunidade de dar início à organização de um livro intitulado "Ernerto Laclau e Niklas Luhmann: Pós-fundacionalismo, abordagem sistêmica e as organizaçôes sociais" (Rodrigues e Mendonça, 2006). A obra visava a uma aproximaçáo entre a Teoria do Discurso de Ernesto Laclau e Chantal Mouffe e a Teoria Stêmica de Niklas Luhmann. Esse foi o momento em que tivemos contato com o texto de Urs Stäheli (1996). A curiosidade desta nota é que, quando Ernesto Laclau esteve no Brasil, na Universidade Federal de Pelotas (UFPel), para proferir a conferência "A construção discursiva dos antagonismos sociais", em $1^{\circ}$ de agosto de 2013 - portanto, menos de um ano antes de seu lastimável falecimento -, fomos indagados por ele sobre o mencionado artigo "Laclau e Luhmann: um diálogo possível”, que fazia parte da referida coletânea. Na ocasiâo, disse-nos que estava de 
acordo com a aproximação - que centralmente coloca sua noçáo de sistema como sistema autorreferente, portanto pós-estruturalista, e pós-fundacionista, e ainda nos perquiriu sobre a possibilidade de uma versão em inglês. O texto de Stäheli (1996) constrói uma leitura muito semelhando à que fizemos posteriormente, mas que destaca o pós-estruturalismo na teoria sociológica luhmanniana, de certa forma diferentemente da desconstrução derridiana. Também fizemos menção a esse fato em Mendonça e Rodrigues (2014a).

3 Essa hermenêutica radical é sustentada pelo conceito de autopoiésis, que propóe uma constante produçâo semântica, considerando a relação/sistema e entorno, conforme Maturana e Varela (1997).

4 Aqui limitar-se-á dizer que a perspectiva teórica de evolução em Luhmann está longe de ser uma mera transposição das principais ideias darwinistas para o conhecimento da sociedade. Em "La sociedad de la Sociedad", Luhmann dedica um capítulo com mais de 100 páginas para discutir o que entende por "evoluçáo" (Luhmann, 2006, cap. 3, p. 325-455).

5 Para uma reflexão atual sobre a semântica em Luhmann, contemplando também aspectos da abordagem pósestruturalista, ver Homes (2018). Para uma reflexão sobre observação, observador, observado e interação, ver Rodrigues (2017).

6 É necessário destacar que esses três elementos básicos constituintes da comunicação - informação, ato de comunicar e ato de entender - só podem ser analisados, separadamente, na observação do processo comunicativo. Durante o acontecimento real da comunicação, no entanto, essas três seleçôes são indissociáveis.

7 A seleção (ou atualização) da informação e o ato de comunicar competem a Alter, de modo que é necessário que seja tomada a iniciativa de interagir para que o processo comunicativo se inicie. Por sua vez, a seleção no ato de entender compete a Ego. Nesse sentido, se Ego não entender o ato de comunicar (o porquê de Alter ter comunicado) e o conteúdo informado (o que foi comunicado por Alter), então, não haverá comunicação. Cabe frisar, todavia, que o entendimento não significa que Ego tenha de saber exatamente os motivos que levaram Alter a comunicar, tampouco que ele saiba precisamente aquilo que Alter quis informar. Antes disso, $\mathrm{o}$ ato de entender se refere ao próprio entendimento que Ego realizou sobre essas duas seleçóes. Isso porque todo entendimento na teoria luhmanniana é sempre um autoentendimento, dado o fechamento operativo sistêmico autopoiético.

8 Na tradição filosófica, considerando-se aquela de origem platônica e hegeliana, poder-se-ia dizer que as teorias de auto-organização, incluindo a autopoiésis, engendram ordem a partir da noção de autocausaçáo. Para uma maior abordagem da auto-organização a partir de uma perspectiva filosófica, ver Cirne-Lima (2003); Rodrigues (2017).

9 Primeiramente, este texto foi fruto de uma conferência proferida por Derrida no Colóquio Internacional da Universidade Johns Hopkins (Baltimore) sobre "As linguagens críticas e as ciências do homem", realizada em 21 de outubro de 1966. Em português, o texto aparece com o título "A estrutura, o signo e o jogo no discurso das Ciências Humanas".

10 Apud Luhmann (1993, p. 763-82).

11 Apud Luhmann (1993, p. 766).

12 A ciência moderna nasceu durante o Renascimento, entre os séculos XVI e XVII. A essa época, o sistema científico se resumia a um número muito limitado de disciplinas: física, química, biologia e matemática. $\mathrm{O}$ processo de disciplinarização do conhecimento teve início com o avanço do desenvolvimento científico, com a descoberta de novos objetos de estudo e com a emergência de novos problemas a serem solucionados. Assim, ao longo do século XIX e da primeira metade do século XX, surgiu um número incomensurável de novas áreas do conhecimento.

\section{BIBLIOGRAFIA}

ALEXANDER, Jeffrey. (1987), "O novo movimento teórico”. Revista Brasileira de Ciências Sociais, São Paulo, v. 2, n. 4, p. 5-28.

ARCHER, Margaret. (1988), Culture and agency: the place of culture in social theory. Cambridge, Cambridge University Press.

ARCHER, Margaret. (2004), Being human: the problem of agency. Cambridge, Cambridge University Press.

ARCHER, Margaret. (2009), Teoría social realista: el enfoque morfogenético. Chile, Ediciones Universidad Alberto Hurtado.

ARNOLD, Marcelo. (2004), "Introducción a las epistemologías sistémico construtivistas", in: OSÓRIO, Francisco. Ensayos sobre socioautopoiesis y epistemología constructivista, p. 7-15. Santiago de Chile, Ediciones Mad.

BASTIDE, Roger. (1971), Os usos e sentidos do termo "estrutura". São Paulo, Editora Herder. 
BOURDIEU, Pierre. (1980), Campo de poder. Buenos Aires, Montressor.

BOURDIEU, Pierre. (2000), O poder simbólico. Lisboa, Difel.

BOURDIEU, Pierre. (2007), El sentido práctico. la ed., Buenos Aires, Siglo XXI.

BOURDIEU, Pierre. (2008), Homo academicus. Buenos Aires, Siglo XXI.

BOURDIEU, Pierre; WACQUANT, Loïc. (2005), Una invitación a la sociología reflexiva. Buenos Aires, Siglo XXI.

CASTELLS, Manuel. (2003), A Galáxia da Internet. Reflexóes sobre a internet, os negócios e a sociedade. Rio de Janeiro, Zahar.

CIRNE-LIMA, Carlos. (2003), "Causalidade e auto-organização”, in: CIRNE-LIMA, Carlos; ROHDEN, Luiz (orgs.), Dialética e autoorganização. São Leopoldo, Unisinos.

CULLER, Jonathan. (1997), Sobre a desconstrução: teoria e crítica do pós-estruturalismo. Rio de Janeiro, Rosa dos Ventos.

DERRIDA, Jacques. (1968), “A estrutura, o signo e o jogo no discurso das ciências humanas, in: COELHO, Eduardo (org.), Estruturalismo: antologia de textos teóricos, p. 101-23, São Paulo, Martins Fontes.

DERRIDA, Jacques. (1995), A escritura e a diferença. São Paulo, Perspectiva.

DERRIDA, Jacques; CAPUTO, John David. (2009), La deconstrucción en uma cáscara de nuez. Buenos Aires, Prometeo Libros.

DOSSE, François. (1993), História do estruturalismo: o campo do signo, 1945/1966. São Paulo, Editora Ensaio.

GIDDENS, Anthony. (1990), As consequências da modernidade. São Paulo, Unesp.

GIDDENS, Anthony. (1993), New rules of sociological method. Califórnia, Stanford University Press.

GIDDENS, Anthony. (2000). Dualidade da estrutura: agência e estrutura. Portugal, Celta Editores.

GIDDENS, Anthony. (2003), A constituição da sociedade. 2. ed., São Paulo, Martins Fontes.

GLYNOS, Jason; HOWARTH, David. (2007), Logics of critical explanation in social and political theory. Nova York, Routledge.
HOMES, Pablo. (2018), "A semântica da complexidade e a sua estrutura social: o materialismo 'pósestruturalista' da teoria dos sistemas", in: Sociologias, ano 20, n. 47, jan./abr., p. 338-68, Porto Alegre.

HUYSSEN, Andréas. (1992), "Mapeando o pósmoderno", in: HOLLANDA, Heloisa B. (org.), Pós-moderno e política. Rio de Janeiro: Rocco.

LACLAU, Ernesto; MOUFFE, Chantal. (1985), Hegemony and Socialist Strategy. Towards a Radical Democratic Politics. London, Verso.

LAHIRE, Bernard. (2002), O homem plural: os determinantes da ação. Petrópolis, Vozes.

LÉVI-STRAUSS, Claude. (2003), Estruturas elementares do parentesco. Petrópolis, Vozes.

LÉVI-STRAUSS, Claude. (2003a), Antropologia estrutural. Rio de Janeiro, Tempo Brasileiro.

LÉVI-STRAUSS, Claude. (1970), Antropologia estrutural. Rio de Janeiro, Tempo Brasileiro.

LUHMANN, Niklas. (1993), "Deconstruction as second-order observing", in: New Literary History, v. 24, n. 4 , p. 763-82.

LUHMANN, Niklas. (1998), Sistemas sociales: lineamentos para una teoría general. México, Anthropos; Universidade Iberoamericana; Santafé de Bogotá; CEJA; Pontificia Universidad Javeriana.

LUHMANN, Niklas. (2016), Sistemas sociais: esboço de uma teoria geral. Petrópolis, Vozes.

LUHMANN, Niklas. (2006), La sociedad de la sociedad. Ciudad de México, Editorial Herder.

LUHMANN, Niklas. (2009a), ¿Como es posible el orden social? México, Editorial Herder.

LUHMANN, Niklas. (2009b), Introdução à teoria dos sistemas. 3.ed. Petrópolis, Vozes.

LUHMANN, Niklas. (1990), Essays on self-reference. New York, Columbia University Press.

MARCHART, Oliver. (2007), Post-foundational political thought. Edinburgh, Edinburgh University Press.

MATURANA, Humberto; VARELA, Francisco. (1997), De máquinas y seres vivos - autopoiésis: la organización de lo vivo. 5.ed., Santiago, Universitaria.

MENDONÇA, Daniel de; RODRIGUES, Léo Peixoto. (2014a), Pós-estruturalismo e teoria do discurso: em torno de Ernesto Laclau, 2a ed., Porto Alegre, Edipucrs. 
MENDONÇA, Daniel de; RODRIGUES, Léo Peixoto. (2014b), "Do estruturalismo ao pós-estruturalismo: entre fundamentar e desfundamentar", in:

MENDONÇA, Daniel de; RODRIGUES , Léo Peixoto. (2006), "Laclau e Luhmann: um diálogo possível”, in: RODRIGUES, Léo Peixoto; MENDONÇA, Daniel de, Ernesto Laclau e Niklas Luhmann: pós-fundacionismo, abordagem sistêmica e as organizaçôes sociais, $1^{\text {a }}$ ed., v. 500, p. 87-99, Porto Alegre, Edipucrs.

MOELLER, Hans-Georg. (2006), Luhmann explained: from souls to systems. Illinois, Open Court, 2006.

NEVES, Clarissa Baeta; NEVES, Fabrício Monteiro. (2006), "O que há de complexo no mundo complexo? Niklas Luhmann e a teoria dos sistemas sociais", in: Sociologias, no 15, p. $182-$ 207, Porto Alegre.

PETERS, Michael. (2000), Pós-estruturalismo e filosofia da diferença. Belo Horizonte, Autêntica.

RODRIGUES, Léo Peixoto. (2017), “Observação e ordem: 'rascunhos' a uma epistemologia do (com)plexus", in $M A D$, n. 37, p. 91-112, Santiago (Chile).

RODRIGUES, Léo Peixoto. (2014), "Platô sistêmico na teoria social: uma revolução científica às avessas", in: Dados - Revista de Ciências Sociais, v. 57, n. 4, p. 1109-35, Rio de Janeiro.

RODRIGUES, Léo Peixoto; MENDONÇA, Daniel de (org.). (2006), Ernesto Laclau e Niklas Luhmann: pós-fundacionalismo, abordagens sistêmicas e as organizaçóes sociais. Porto Alegre, Edipurs.

RODRIGUES, Léo Peixoto; NEVES, Fabrício Monteiro. (2012), Niklas Luhmann: a sociedade como sistema. Porto Alegre, Edipucrs.

RODRIGUES, Léo Peixoto; NEVES, Fabrício Monteiro. (2017), A sociologia de Niklas Luhmann. Petrópolis, Vozes.

STÄHELI, Urs. (2006), “The post-structuralism”, in: HARRINGTON, Austin; MARSHALL, Barbara L.; MÜLLER, Hans-Peter (orgs), Encyclopedia of social theory, p. 453-481, Estados Unidos; Canadá, Routledge.

STÄHELI, Urs. (1996), "Der Code als leere Significant? Diskurstheoretische Betrachtungen", in: Soziale systeme, v. 2, p. 257-81, Bielefeld, Universität Bielefeld.

STICHWEH, Rudolf. (2012), "El concepto de sociedad mundial. Génesis y formación de estructuras de un sistema social global", in: CADENAS, Hugo; MASCAREÑO, Aldo; URQUIZA, Anahí (eds.), Niklas Luhmann y el legado universalista de su teoría. Aportes para el análisis de la complejidad social contemporánea, p. 23-48, Santiago, RIL Editores.

TEUBNER, Ghunter (org.). (2008), "Die Erblast”. In: Nach Jaques Derrida und Niklas Luhmann: Zur (Un-) Möglishkeint einer Gesellchaftstheorie der Gerechtigkeit, p. 2-7, Stuttgard, Lucius \& Lucius. 


\section{O PÓS-ESTRUTURALISMO SISTÊMICO DE NIKLAS LUHMANN}

Léo Peixoto Rodrigues, Everton Garcia da Costa

Palavras-chave: Niklas Luhmann, Pós-estruturalismo, Complexidade, Pósdeterminismo, Relacionalidade.

$\mathrm{O}$ artigo apresenta a teoria sistêmica de Niklas Luhmann, discutindo seus principais conceitos, criticamente, e destacando-lhes características pós-estruturalistas comuns a boa parte da teoria sociológica contemporânea. $\mathrm{O}$ argumento de fundo - e o que de fato se busca demonstrar - é que os mesmos fatores teórico-filosóficos que geraram a crise da metafísica, do humanismo como pilar da teoria sociológica clássica, e a crise do determinismo científico influenciaram a teoria sistêmica de Luhmann, sobretudo a partir de sua "virada autopoiética", na década de 1980. Para tanto, exploram-se conceitos tais como: descentramento, desconstruçáo, desfundamentaçáo, complexidade, sistemaentorno, comunicação, relacionalidade, dentre outros que também estão presentes no que se está chamando de teoria sistêmica pós-estruturalista de Niklas Luhmann.

\section{NIKLAS LUHMANN'S SYSTEMIC POST-STRUCTURALISM}

\section{Léo Peixoto Rodrigues, Everton Garcia da Costa}

Keywords: Niklas Luhmann, Poststructuralism, Complexity, Post-determinism, Relationality.

This article presents Niklas Luhmann's systemic theory, critically discussing its main concepts, and highlighting poststructuralist characteristics common to much of contemporary sociological theory. The bottom line - and what we are really trying to demonstrate - is that the same theoretical-philosophical factors that generated the metaphysics crisis, of humanism as the mainstay of classical sociological theory, as well as the scientific determinism crisis, influenced Luhmann's systemic theory, especially from its "autopoietic turn", in the 1980s. To this end, concepts such as decentralization, deconstruction, de-structuring, complexity, system-surroundings, communication and relationality are explored, among others that are also present in what is termed Niklas Luhmann's post-structuralist systemic theory.

\section{LE POSTSTRUCTURALISME SYSTÉMIQUE DE NIKLAS LUHMANN}

\section{Léo Peixoto Rodrigues, Everton Garcia da Costa}

Mots-clés: Niklas Luhmann, poststructuralisme, complexité, postdéterminisme, relationnel.

Cet article opère une discussion critique des concepts principaux de la théorie des systèmes de Niklas Luhmann et met en évidence les caractéristiques poststructuralistes communes à une grande partie de la théorie sociologique contemporaine. L'objectif est de démontrer que les facteurs théoricophilosophiques qui ont entraîné la crise de l'humanisme comme pilier de la théorie sociologique classique, de la métaphysique et du déterminisme scientifique, sont les mêmes que ceux qui ont influencé la théorie des systèmes de Luhmann, surtout à partir de son «tournant autopoïétique " dans les années 1980. Dans ce sens, plusieurs concepts sont analysés: décalage, déconstruction, sans fond, complexité, système-environnement, communication, relationnel et d'autres qui sont aussi présents dans ladite théorie des systèmes poststructuraliste de Niklas Luhmann. 